\title{
Perspectives on Structuralism
}

\author{
Holger Andreas • Frank Zenker
}

Received: 27 September 2013/ Accepted: 27 September 2013/Published online: 7 December 2013

(C) Springer Science+Business Media Dordrecht 2013

This issue of Erkenntnis collects papers presented at the international conference Perspectives on Structuralism held in February 2012 at the Center for Advanced Studies of LMU Munich. The editors gratefully acknowledge the generous support from the Center for Advanced Studies. Moreover, we are most grateful to a number of referees on whose judgment our editing decisions have been based.

The Munich conference on the structuralist approach was motivated, first, by novel developments concerning the structuralist meta-theory and, second, by the relevance of ongoing research for current issues in general philosophy of science. The range of topics addressed is broad-including theoretical terms and concepts, causation, explanation, social processes, the syntactic approach to scientific theories, quantitative science studies, and the dynamics of science. Below, we give a brief introduction to the basic concepts of the structuralist approach, addressed to the uninitiated reader. We take this special issue to evidence that structuralist insights and methods remain applicable well beyond the reconstruction of an empirical theory's mathematical structure.

\footnotetext{
H. Andreas $(\square)$

Munich Center of Mathematical Philosophy, Munich, Germany

e-mail: holger.andreas@1rz.uni-muenchen.de

F. Zenker

Lund University, Lund, Sweden
} 